\title{
Factors influencing post-partum women's choice of an implantable contraceptive device in a rural district hospital in South Africa
}

\author{
Francois Potgieter ${ }^{a}$, Paul Kapp ${ }^{a}$ and Francois Coetzee ${ }^{b *}$ (D) \\ ${ }^{a}$ Department of Family and Emergency Medicine, Stellenbosch University, Knysna, South Africa \\ ${ }^{b}$ Ukwanda Centre for Rural Health, Stellenbosch University, Worcester, South Africa \\ *Corresponding author, email: franna@sun.ac.za
}

Background: A single-rod subdermal contraceptive implant containing $68 \mathrm{mg}$ of etonogestrel, ImplanonNXT ${ }^{\circledR}$, was introduced to the South African healthcare system in 2014. Initially the new device was well received but later uptake tapered off. A need was identified to determine the factors that influence women's choices with regard to the use of ImplanonNXT ${ }^{\circledR}$ in order to improve its uptake. The aim of this study was to explore the factors that influence women's choice of ImplanonNXT ${ }^{\oplus}$.

Method: A qualitative study was performed, using semi-structured interviews to explore patients' knowledge, attitudes and beliefs regarding ImplanonNXT ${ }^{\oplus}$. Ten patients were interviewed at Knysna Hospital.

Findings: There was confusion amongst women about the harms and benefits of using ImplanonNXT ${ }^{\circledR}$ and it became apparent contraceptive counselling during pregnancy greatly affects the choices they make. Other factors that influenced the participants' choice with regard to contraception included social influences, preference for familiar methods and the side effect profile of the various options.

Perceptions of the adverse side effects of the implantable device added to confusion and fear of this method, which influenced women's ideas about the use of ImplanonNXT ${ }^{\oplus}$. Poor communication and reluctance from clinic staff to discuss ImplanonNXT ${ }^{\oplus}$ during antenatal visits contributed to poor knowledge about the implantable device and its side effects.

Conclusion: Clearer communication during antenatal visits with pregnant women may address some of the fears and beliefs that surround its side effects, workings and efficacy. The fear of possible side effects should be a focus for counselling and education, as it predominantly contributes to women's confusion and fear of the device. Further research is needed to address this as well as evaluate if interventions such as better counselling and a dedicated team approach can change the attitudes and beliefs of post-partum women towards the ImplanonNXT ${ }^{\oplus}$ device in the South African district health system.

Keywords: long acting reversible contraception, barriers, post partum, perceptions, choice

\section{Introduction}

The South Africa Demographic and Health Survey report released in 2017 indicated that about $58.3 \%$ of women use some form of contraception ${ }^{1}$. During this time in the Eden district of the Western Cape Province the majority of women reported using injectables (71\%) while $24 \%$ used oral contraceptives. Some $13 \%$ of women reported making use of the intrauterine contraceptive device (IUCD) while less than $1 \%$ used ImplanonNXT® ${ }^{\oplus}$, the other long-acting reversible contraception (LARC) available in the Eden district. ${ }^{2}$

ImplanonNXT ${ }^{\circledR}$ was introduced to South Africa in 2014, adding a second LARC option for women in addition to the IUCD. ImplanonNXT ${ }^{\oplus}$ was launched in South Africa and not Implanon ${ }^{\oplus}$. Even though they are the same contraceptive, the ImplanonNXT ${ }^{\circledast}$ contains Barium and has a specially designed applicator to avoid deep insertions. For the rest of the article ImplanonNXT ${ }^{\circledR}$ will be referred to as Implanon ${ }^{\oplus}$. The Department of Health $(\mathrm{DOH})$ invested a lot of time and finances into making this new protective device available to all, since it was promoted to increase the 'couple year protection rate', provide better family spacing and decrease unwanted pregnancies. ${ }^{3}$

Healthcare workers also promoted this new LARC as a method of contraception in the postpartum period, but since 2015 its popularity in South Africa has decreased significantly. ${ }^{4}$

The decline in use of the implantable device in the areas surrounding Knysna Hospital was also evident in the local subdistrict maternal health statistics. It showed a $50.0 \%$ decrease in ImplanonNXT ${ }^{\oplus}$ uptake from 48 to 24 units per month over a 16 -month period. ${ }^{5}$

This initial acceptance by postpartum women and the subsequent rapid decline begs the question as to what factors influenced their decision.

LARCs like ImplanonNXT ${ }^{\circledR}$ have been in use since 1998. Implanon ${ }^{\circledR}$ was first introduced in Indonesia, and subsequently approved for use in over 60 countries by $2003 .^{6}$ It showed a much better continuation rate and similar side-effect profile when compared with other contraceptive devices. ${ }^{7-10}$ Previous studies from Thailand and Ethiopia have shown that proximity to health care, women's age and education can play a role in their choice of contraception. ${ }^{11,12}$ Other factors that determine the choice of contraception are partner preference and the cost of contraception. ${ }^{10,13}$

Knysna Hospital, situated in the Garden Route of the Western Cape in South Africa, serves a significant population and there are about 50000 women seeking family planning services each year. ${ }^{14}$ As only 170 IUCDs were inserted in the two subdistricts during 2013, the acceptance of this method seemed to be low. ${ }^{14}$ Local hospital labour ward statistics showed that the three-month injectable contraceptive was the most common method chosen by postpartum women. ${ }^{14}$ Previous investigators have found that women tend to choose the contraceptive method advocated by their healthcare providers. ${ }^{11,15}$ At present there is a need in South 
Africa to better understand the extent and reasons for a decline in use of the implantable device. ${ }^{16}$ The aim of this study was to explore the factors that influence women's choice of ImplanonNXT ${ }^{\oplus}$ in the South African context.

\section{Methods}

\section{Setting}

The town of Knysna has a large divide between rich and poor with the biggest portion of the population dependent on the government health system. In 2011, 24.8\% of the Knysna population were unemployed and $73 \%$ lived in formal dwellings. ${ }^{17}$ The hospital acts as the drainage area for two subdistricts with a combined population of 120000 people. ${ }^{17}$ These districts are Knysna (60 000) and Bitou (Plettenberg Bay, 60 000). In Knysna and Bitou the majority of the population are Africans or mixed ethnicity people and dependent on the government health system. The mixed ethnicity population are mainly Christian, while the majority of the Africans follow their own cultures.

The study was done at Knysna provincial hospital. The labour ward is the only maternity unit in the subdistricts of Knysna and Bitou. There is an average of five to six live births per day, with a Caesarean section rate of between $20 \%$ and $30 \%$. The teenage pregnancy rate for 2016 was $14.0 \% .^{18}$

All women attending antenatal visits at their primary health clinics are counselled during their pregnancy. Contraceptive counselling forms part of these routine visits, which are mainly managed by professional nursing staff. Contraceptive counselling is done again after delivery, and previously documented decisions are checked before contraception is administered. This task is the responsibility of the professional nursing staff of the labour ward and forms part of their many duties post-delivery.

\section{Sampling}

The study population consisted of all postpartum women who delivered at Knysna Provincial hospital labour ward between February 2015 and August 2015. Purposive sampling was used: women in the labour ward were asked if they were willing to participate in the study. Willing women who did not possess any of the exclusion criteria were interviewed. Women were excluded if they were unable or did not consent, did not speak English, Afrikaans or Xhosa, were younger than 18 years of age (due to consent), or had any contraindications to the implantable contraceptive device. Two women declined to participate in the study claiming time and transport restrictions.

\section{Data collection}

Semi-structured individual interviews with 10 participants were conducted by the researcher, making use of a discussion schedule (see Appendix A) that provided guidance, but was not strictly adhered to, to allow for new topics to be developed. Interviews were conducted in English or Afrikaans and translated into English.

\section{The following topics were explored:}

- Patients' knowledge and ideas regarding their current contraceptive method;

- Patients' knowledge regarding the implantable contraceptive device;

- Patients' personal and reproductive circumstances that may influence choice;

- Patients' perceptions of the implantable contraceptive device;
- Any factors that may influence the choice of an implantable device.

The discussion schedule was based on knowledge of factors that play a role in the choice of contraception in women in their reproductive years. ${ }^{19,20}$ To ensure that the patients were comfortable, the interviews were held in a private room within the hospital to minimise interruptions. All interviews were audiorecorded and transcribed verbatim. A research diary was kept by the researcher with field notes containing extra information during interviews, which was added to the transcripts.

\section{Data analysis}

The transcribed data were analysed using the framework method. ${ }^{21}$ The researcher immersed himself in the data, and a thematic index was developed by coding the data and organising the codes into categories using the Atlas-ti (https://atlasti.com/) qualitative analysis software. The transcripts were indexed by systematically applying the codes in the thematic index to all the data. Charting was done to bring together all data that had the same codes. These were then interpreted by the researcher to identify the range and depth of different themes and any relationships between themes. The field notes assisted with developing the themes and further analysis of the data. Validity was tested by respondent validation of the conclusions. Results were confirmed with interviewees by phone after the study data were analysed.

\section{Trustworthiness}

To ensure trustworthiness of the study three constructs were utilised. ${ }^{22}$ The researcher ensured that sufficient contextual information was provided on the participants and the research setting to enable the reader to judge whether the results are transferable to other settings and could be replicated in other settings. For confirmability, a reflexive paragraph was added by the researcher to explain the view taken by the researcher. An independent transcriber was used, and the accuracy of the transcriptions was checked against the original recordings.

\section{Reflexive paragraph}

The researcher is a Caucasian, Afrikaans-speaking South African male in his thirties working as a Family Medicine registrar in the Knysna and Bitou sub-districts and interested in improving the couple-year contraceptive protection rate.

\section{Ethical considerations}

The study was approved by the Stellenbosch University Health Research Ethics Committee (HREC approval no. S14/07/149) and permission obtained from the Western Cape Department of Health (WC_2015RP50_54). The research was conducted in agreement with the Helsinki ethical code of conduct, the South African Council for Good Ethical Practice and the Medical Research Council Ethical Committee for Research.

\section{Findings}

Four themes were identified with regard to factors that influence women's choice of LARC in the postpartum period (see Figure 1).

\section{Demographics}

Participants were between the ages of 23 and 35 with six being of the coloured race. Four were unemployed and three from a middle-income group. All participants were in a relationship with only three of them married. The majority were of the Christian religion. 


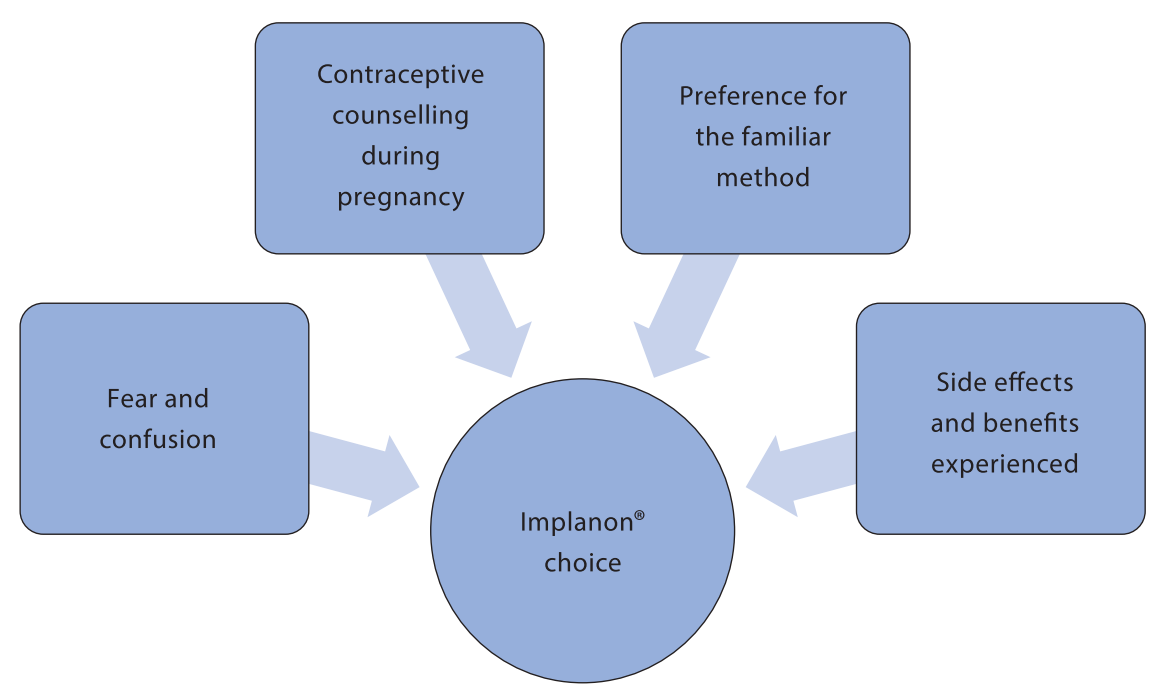

Figure 1: Factors influencing women to choose or avoid Implanon ${ }^{\circledast}$.

Quotes were assigned tags to link them with the participants. Each participant was assigned a number and $\mathrm{R}, \mathrm{E}$ and $\mathrm{M}$ represent whether they are in a relationship, engaged or married. For example ' $\mathrm{M} 4,25$ ' indicates participant number 4 , and that she is married and 25 years of age (see Table 1).

\section{Theme 1: fear and confusion}

Many of the participants are of the opinion that social and personal factors influence their choice of contraception. While their partner's opinion, family responsibility and financial factors increased fear surrounding the device, the opinions of the general public, family, friends and the media were also negative towards Implanon ${ }^{\circledR}$, contributing to the women's fear of this new device and increasing the confusion surrounding contraceptive choice. As a result, many women became sceptical about the LARC. They avoided its use, which decreased the device's acceptance amongst participants.

Some married women suggested that input from husbands could affect their contraceptive choice, while others thought that it is their sole responsibility to ensure that they are protected against pregnancy:

'It is you, you as a woman have a huge responsibility. You can either have intercourse with a condom which is not hundred per cent; you don't have to tell your partner you have the implant, because why I'm saying that is because he is just going to tell you some stage to have it removed.' $[R 3,26]$

For some participants, being employed seemed to have little to no influence on their choice of contraception. Others feared losing their employment because of absences from work and that the implantable contraceptive device meant that they do not have to go to the clinic and miss work at all for three years:

'I think the implant is better.... So you must go to the clinic every time for the pill. And the implant is something inside you, and it lasts long .... You're at work every day if you use it.' $[R 9,23]$

Some women were of the opinion word of mouth contributes to negative perceptions, that once formed are tough to change.
Implanon ${ }^{\circledast}$ is no exception as fearful beliefs concerning the physical side effects spread amongst the female population:

'What I can say is what I have heard, your body build changes, you lose weight or your skin, something is wrong with your skin. Almost like rash or something, hair loss. It is almost like, as the side effects, it is almost like stress.' [R3,26]

Confusion was created as patients found the information from the public contradicted what was discussed at the clinic. Some felt that public opinion outweighs the promotion done by healthcare workers:

II really do not know. Everything is confusing then I am not sure whether to believe the doctors or the other people, but after talking to other people I decided not to [take the device].' $[R 8,23]$

Some interviewees claimed that they were influenced by what they heard on the radio. This led to doubt about the device and caused participants to fear the efficacy of the device and its side effects:

I've heard on the radio that some of the other women who put the Implanon ${ }^{\circledast}$ on are wanting to take it off, I don't know the main reason why in the Eastern Cape and they say it also causes, I don't know what's this thing ... . I forgot about it now, but they say it.' $[R 7,19]$

\section{Theme 2: contraceptive counselling during pregnancy}

Counselling about contraception choice post-delivery happens during the first antenatal clinic visit. This decision is documented and confirmed postpartum before contraception administration. The healthcare workers' counselling approach, information sharing and product promotion were identified as factors within our healthcare system that have an influence on women's beliefs about and perception of Implanon ${ }^{\circledR}$.

Women mentioned that the way in which the topic was approached discouraged them from discussing contraceptive options. This approach led to them not taking part in this critical decision-making moment and left them with little information about the device: 
Table 1: Demographics of participants

\begin{tabular}{|c|c|c|c|c|c|c|c|c|}
\hline Age & Race & Parity & Delivery & Education & Income & Relationship & Religion & Residence \\
\hline 35 & W & 2 & $\mathrm{C} / \mathrm{S}$ & Tertiary & Middle income & Married & Christian & Knysna \\
\hline 32 & B & 2 & $\mathrm{C} / \mathrm{S}$ & Matric & Low income & Married & Atheist & Knysna \\
\hline 26 & C & 2 & NVD & Gr11 & Unemployed & Relationship & Christian & Plettenberg Bay \\
\hline 27 & $C$ & 1 & $\mathrm{C} / \mathrm{S}$ & Diploma & Low income & Relationship & Christian & Plettenberg Bay \\
\hline 33 & $C$ & 2 & $\mathrm{C} / \mathrm{S}$ & Tertiary & Middle income & Engaged & Christian & Knysna \\
\hline 23 & C & 3 & NVD & Gr9 & Unemployed & Married six years & Christian & Sedgefield \\
\hline 19 & B & 1 & $\mathrm{C} / \mathrm{S}$ & Matric & Unemployed & Relationship & Christian & Plettenberg Bay \\
\hline 23 & $C$ & 1 & $\mathrm{C} / \mathrm{S}$ & Gr9 & Unemployed & Relationship & Atheist & Plettenberg Bay \\
\hline 23 & C & 1 & NVD & Matric & Low income & Relationship & Christian & Sedgefield \\
\hline 28 & W & 1 & NVD & Matric & Middle income & Relationship & Christian & Knysna \\
\hline
\end{tabular}

$\mathrm{C} / \mathrm{S}=$ Caesarean section; NVD = normal vaginal delivery.

\begin{abstract}
'I have sat in the clinic a couple of times where nurses, for instance, would lecture everyone who sits there .... I think that the thing for me was when I went to the clinic I got a feeling even though I'm a married woman and I've got a job, and I'm not you know, some you know random person, that you are almost treated as if you have been very irresponsible.' [M1,35]
\end{abstract}

The timing of counselling seemed to be of concern as some interviewees claimed that they did not need contraception counselling once they were already pregnant and the focus should fall more on non-pregnant women:

'They did, they did say something about the implant, but maybe it's because I was not paying any attention to .... . I was already pregnant, yes, so I couldn't find a reason to listen to what they were saying at that time.' $[R 7,19]$

Participants felt that if they had more information about the device, they would be less confused, less fearful and have less doubt. For women to accept an implantable device for three years, more information is needed for them to feel comfortable with this new method of contraception. The lack of information led to little knowledge about the device and left one participant confused and with more questions than answers about its functionality:

'They say it is like a snake thing. I'm asking myself how is it possible to go in the arm, is there a way how the body can, why in the arm when things happen below. That is tricky.' $[R 4,27]$

Many women felt that not enough was being done at clinic level to support the device and advocate its use. They felt that better awareness of the instrument might convince women to accept it as their first-choice contraceptive:

'Yeah, they ask you after birth, which contraception are you going to use? Yeah, but they didn't explain anything about the implant and stuff.' [M2,32]

\section{Theme 3: preference for the familiar method}

According to some respondents, a major factor influencing women not to use the implantable contraceptive device was being familiar with their previous method of contraception. There were participants who were happy with their current contraceptive method and gave various reasons why they were reluctant to change.
Women were not prepared to experiment if their current contraception was working and they were not experiencing any problems:

I'm happy, I stick with what I'm having; I never had any problems.' [E5,33]

Some women who experienced side effects from their current contraceptive method nevertheless felt that they would rather stick with it than change to a method that was new and unfamiliar:

'I guess it is the devil you know ... because you know there is a week in that cycle that I'm going to start getting grumpy because it always happens. So that is, you kind of know exactly what you are dealing with; I mean as if I have the implant, I can't just pull it out if it is, you know, causing distress. And then you've got to learn all over again, you know, how to handle that.' $[\mathrm{M} 1,35]$

\section{Theme 4: side effects and benefits experienced}

Women mentioned many product-related factors that affected their acceptance of the contraceptive device. Although the side effects influenced some women not to use the device, for others the advantages and ease of use made it their preferred method of choice.

All women received counselling about the side-effect profile of the implantable contraceptive device. Some women were not prepared to take the risk of experiencing any of the wellknown side effects:

'There are some of them who had removed it when they got headaches and dizziness, and there are also people who bleed nonstop. So that is why I have decided not to use it.' $[R 8,23]$

Many women who chose Implanon ${ }^{\circledR}$ did so for its three-year protective cover compared with the shorter cover provided by competing products. Other benefits mentioned were the simple procedure of acquiring the device and removal thereof:

'It is actually, it is almost like a little "close matter" [referring to sterilisation] that they actually do for you, for three years you are closed, after the third year you can close up again or you can have it removed ... it is only a 
needle they took and, but you don't feel anything, it is almost like an injection.' [R3,26]

When participants compared Implanon ${ }^{\circledR}$ with their previous choices of contraception (many were on an injectable contraception), the implantable device was the preferred method due to the ease of use:

'I don't have a problem with the Depo, but since we have to always have to go three months, three months, at least three years you get peace of mind.' [M2,32]

\section{Discussion}

While some women were favourably disposed towards the new LARC method, the themes that we identified left women uncertain or negative about using the new implantable device in the postpartum period and led to a decline in acceptance.

This study suggests that confusion and community perceptions also play a significant role in the modest use of the method. This importance of public perceptions when it comes to making a choice in method for contraception is not to be underestimated and there is the risk of misconceptions becoming embedded in communities. ${ }^{23}$ In 2016 Pillay et al. interviewed 152 women who attended clinics in the city of Johannesburg and had had implants inserted. They found that $60 \%$ of users had the Implanon ${ }^{\circledR}$ removed within 12 months and $90 \%$ of all the users who had it removed indicated that it was due to side effects. ${ }^{23}$

The data from this study suggests that this an important aspect to consider, since a number of woman who were negatively inclined towards the implantable device were exposed to women who experienced side effects and had the device removed.

This study looked at the reasons why woman avoided using Implanon ${ }^{\circledast}$ or chose to use it, and it became apparent that side effects experienced by users and other community members had a negative influence when patients considered using Implanon ${ }^{\oplus}$. A number of studies looked at reasons for having the Implanon ${ }^{\circledR}$ removed and found it was mostly due to side effects experienced, of which changes in vaginal bleeding was the commonest when they investigated the reasons for premature removal of the implantable device. ${ }^{23-26}$

Women who received better information about the implantable device displayed a positive attitude towards it as a contraceptive choice. Similar to previous studies, it was found that acceptance is much better if health staff advocated the device. ${ }^{27,28}$ All pregnant patients in the Knysna district have access to clinics and attend antenatal visits during their pregnancy. This is where contraception should be discussed and planned, and all questions regarding the new implantable contraceptive device answered. All mothers interviewed have attended antenatal visits and were in contact with the health system to discuss their contraceptive concerns and choice after delivery. Despite this we found that knowledge concerning the available contraceptive methods among the postpartum participants remained inadequate. Previous interventions in Zambia have shown better acceptance of LARC by making use of trained, dedicated providers to counsel and distribute contraception. ${ }^{29}$ This reinforces the importance of an adequate proper contraceptive discussion with our patients during antenatal clinic visits to empower women to make informed decisions regarding their choice of family planning. This is also strongly supported by the recent work of Adeagbo et al. ${ }^{30}$

Some mothers with a good understanding of the implantable method believed that it is a convenient choice of contraception. This study found that the side effects experienced by Implanon ${ }^{\oplus}$ users negatively influenced the decisions of possible future users in the community. Similar results were found in an Ethiopian study where women reported having a negative attitude towards long acting contraceptive methods (LACM) due to allegations of side effects among the community. ${ }^{31}$

In this study women who were exposed to positive feedback displayed a favourable attitude towards the Implanon $^{\circledR}$ and were willing to accept the device. This finding is encouraging but contradicts findings in the First World where only $20 \%$ of women found that peers influenced their contraceptive choice. ${ }^{32}$

All interviewees were either married, engaged or in a relationship. Although it was mentioned that marriage might entitle the husband to be more involved in the decision-making process, the contraceptive choice appeared to be mainly the responsibility of the women. Some women were adamant that their partner had little influence in their decision. This is in direct contrast with the study done in Ethiopia where they found a significant reduction in LACM use if the partner did not agree with their choice of contraception and two-thirds of the women obtained permission from their partners before using LARC. ${ }^{31}$ The participants in our study had full autonomy in their choice of contraception and did not have to ask permission before choosing their method of contraception. At most, the women admitted that it might be a discussion or shared decision-making process. The reason for this contrast in results might be due to cultural and religious differences between South African communities and those in rural Ethiopia and the fact that all study participants in the Ethiopian study were married.

Pleaner et al. recently made several recommendations to support South Africa's implantable device programme and many of them are supported by the findings of this study. ${ }^{4}$

The recommendations that are echoed by our findings include:

- Capacity building of healthcare providers with a focus on the bettering of healthcare workers' counselling skills and making them more patient centred;

- Increasing demand for the implantable device by dispelling myths, addressing fears and ensuring that the community has accurate information about the device.

It is uncertain how well the side effects of Implanon ${ }^{\circledast}$ are managed at clinic level.

There were several limitations to this study as it was conducted at a single site which greatly limits the transferability of the data. Interviews were performed by a single interviewer who was easily identifiable as a physician working at the institution, which may have brought about some bias in the gathering of data. The interviews were conducted in the labour ward and this may have increased the hierarchical power differential between the interviewer and the interviewees. This may have restricted women from discussing ideas freely. The study performed by Pillay et al. suggests it would have been better to gather data on the perceptions of patients coming to the 
clinics for contraceptive services, since many patients who chose the Implanon ${ }^{\circledast}$ self-presented to primary facilities after hearing about the device from family members and community members. ${ }^{23}$

\section{Conclusion}

Although the public sector has made a significant investment in the launching and implementation of the implantable device in South Africa, this study and others have found that the use of this LARC has met with many challenges and a decline in popularity. ${ }^{4,23,25}$ This study identify key areas that influence women's decision-making and attitude towards the Implanon ${ }^{\circledast}$ device and its acceptance as contraceptive method of choice in the postpartum period, and highlights the role of information sharing with our patients with regard to contraceptive choices.

Further research is needed to investigate this and evaluate whether interventions such as better counselling and a dedicated team approach can change the attitudes and beliefs of postpartum women and communities towards the Implanon ${ }^{\circledast}$ device in the South African district health system.

Acknowledgement - A special word of thanks to Professor Marietjie De Villiers and Dr Judy Kluge. The authors acknowledge their valuable inputs and assistance in preparing the manuscript

Competing interests - The authors declare that they have no competing interests.

Funding - None

\section{ORCID}

Francois Coetzee (D) http://orcid.org/0000-0002-1408-5813

\section{References}

1. South Africa Demographic and Health Survey 2016: Key indicators. Pretoria, South Africa, and Rockville, Maryland, USA: NDoH, Stats SA, SAMRC, and ICF. 12-18.

2. Eden district contraceptive statistics, 2016/2017 Unpublished data.

3. Lewis LN, Dorota DA, Hickey $M$, et al. Implanon as a contraceptive choice for teenage mothers: a comparison of contraceptive choices, acceptability and repeat pregnancy. Contraception. 2010;81(5):421-6.

4. Pleaner M, Morroni C, Smit J, et al. Lessons learnt from the introduction of the contraceptive implant in South Africa. S Afr Med J. 2017 Nov 1;107(11):933-8.

5. Eden district Implanon register for Knysna Provincial Hospital.

6. Raymond E, Hatcher I, Robert A, et al. Contraceptive implants. Contracept Technol. 2011;19:144-56.

7. Templeman C, Cook V, Goldsmith J, et al. Postpartum contraceptive use among adolescent mothers. Obstet Gynecol. 2000 May;95 (5):770-6.

8. Peipert JF, Zhao Q, Allsworth JE, et al. Continuation and satisfaction of reversible contraception. Obstet Gynecol. 2011 May;117(5):1105-13.

9. Frost JJ, Darroch JE. Factors associated with contraceptive choice and inconsistent method use, United States, 2004. Int Perspect Sex Reprod Health. 2008 Jun;40(2):94-104.

10. O'Neil-Callahan M, Peipert JF, Zhao Q, et al. Twenty-four-month continuation of reversible contraception. Obstet Gynecol. Nov 2013;122 (5):1082-91.
11. Entwisle B, Rindfuss RR, Guilkey DK, et al. Community and contraceptive choice in rural Thailand: a case study of Nang Rong. Demography. 1996 Feb;33(1):1-11.

12. Asnake M, Henry EG, Tilahun Y, et al. Addressing unmet need for long acting family planning in Ethiopia: uptake of implanon and characteristics of users. Pathways 2012 Aug.

13. de Irala J, Osorio A, Carlos S, et al. Choice of birth control methods among European women and the role of partners and providers. Contraception. 2011;84:558-64.

14. Family planning statistics of Knysna District Hospital, 2013 Unpublished data.

15. Wong RC, Bell RJ, Thunuguntla K, et al. Implanon users are less likely to be satisfied with their contraception after 6 months than IUD users. Contraception. 2009;80:452-6.

16. Pillay D, Morroni C, Pleaner M, et al. Gaps in monitoring systems for Implanon NXT services in South Africa: an assessment of 12 facilities in two districts. S Afr Med J. 2017 Oct;107(10):827-31.

17. Statistics South Africa[online]. Oct 2011. Available from: http://beta2. statssa.gov.za.

18. PIPP data of Knysna District Hospital, 2013 Unpublished data.

19. Egarter C, Grimm C, Nouri K, et al. Contraceptive counselling and factors affecting women's contraceptive choices: results of the CHOICE study in Austria. Reprod Biomed Online. 2012 Jun;24 (7):692-97.

20. Hollander D. Bangladeshi women weigh a variety of factors when choosing a contraceptive. Int Fam Plan Perspect. 2003 Mar;29(1):50.

21. Ritchie J, Spencer L. Qualitative data analysis for applied policy research. In: Bryman A, Burgess RG, editors. Analysing qualitative data. London: Routledge; 1994. p. 173-94. http://dx.doi.org/10. 4324/9780203413081_chapter_9.

22. Shenton A. Strategies for ensuring trustworthiness in qualitative research projects. Educ Inf. 2004 Jan;22:63-75.

23. Pillay D, Chersich MF, Morroni C, et al. User perspectives on Implanon NXT in South Africa: a survey of 12 public-sector facilities. S Afr Med J. 2017 Oct;107(10):815-21.

24. Bahamondes L, Brache V, Meirik O, et al. A 3-year multicentre randomized controlled trial of etonogestreland levonorgestrel-releasing contraceptive implants, with non-randomized matched copperintrauterinedevice controls. Hum Reprod. 2015;30(11):2527-38.

25. Obijuru L, Bumpus S, Auinger P, et al. Etonogestrel implants in adolescents: experience, satisfaction, and continuation. J Adolesc Health. 2016;58:284-9.

26. Mutihir JT, Nyango DD. One-year experience with Implanon subdermal implants in Jos, Nigeria. Niger J Clin Prac. 2010;13(1):28-31.

27. Tang JH, Dominik R, Re S, et al. Characteristics associated with interest in long-acting reversible contraception in a postpartum population. Contraception. 2013;88:52-7.

28. Polaneczky M, Slap G, Forke C, et al. The use of levonorgestrel implants (Norplant) for contraception in adolescent mothers. N Engl J Med. 1994;331(18):1201-6.

29. Neukom J, Chilambweb J, Mkandawireb J, et al. Dedicated providers of long-acting reversible contraception: new approach in Zambia. Contraception. 2011;83:447-52.

30. Adeagbo OA, Mullick S, Pillay D, et al. Uptake and early removals of Implanon NXT in South Africa: perceptions and attitudes of healthcare workers. S Afr Med J. 2017 Oct;107(10):822-6.

31. Alemayehu M, Kalayu A, Desta A, et al. Rural women are more likely to use long-acting contraceptive in Tigray region, Northern Ethiopia: a comparative community-based cross-sectional study. BMC Womens Health. 2015;15:71.

32. Gosavi $A$, Ma $Y$, Wong $H$, et al. Knowledge and factors determining choice of contraception among Singaporean women. SMJ. 2016 Nov;57(11):610-15. 


\section{Appendix A}

\section{Discussion schedule}

Introductions; discuss what the research is about and why participant was chosen, address confidentiality and get a consent form signed.

Confirm characteristics (age, parity, education, marital status etc.) to ensure proper representation of the population.

'As the new implantable contraceptive is new to everyone, the medical staff and the patients, we are trying to understand why woman choose to use or not to use it so that we can improve the acceptance rate of it.'

Main question: 'I'd like for you to tell me what contraception you choose to use?'

*How does it make you feel? /What do you think about it?

Knowledge of contraception

What do you know about implantable contraception?

Is it an effective contraceptive method?

How long does it work for?

What do you know about other available contraceptive choices?

What do you know about the side effects of the implantable and other contraceptive methods?

Personal and reproductive circumstances that can influence decisions

How old were you when you were first pregnant?

Wanted/planned pregnancy?
How many children do you have?

Do you want more children?

What contraception does your husband prefer?

Does work have any influence on your choice of contraception?

HIV status?

Positive and negative perceptions of the implant What bad stories have you heard about the implant?

What good stories have your heard about the implant?

What do you think?

Any factors that can lead to an increase in acceptance of the implant

When the nurse/doctor tells you about contraception, what do you want to know?

Can you think of anything that will influence other women to choose the implant?

Did anyone talk to you about the use of the implant during your pregnancy?

What do you think should be the man's responsibility towards contraception?

How were you counselled about contraception during your pregnancy? 